Original Research Paper

\title{
Selecting Natural Fibers for Bio-Based Materials with Conflicting Criteria
}

\author{
${ }^{1,2}$ Faris M. AL-Oqla, ${ }^{1,2}$ Mohd Sapuan Salit, ${ }^{2,3}$ Mohamad Ridzwan Ishak and ${ }^{1}$ Nuraini Abdul Aziz \\ ${ }^{I}$ Department of Mechanical and Manufacturing Engineering, Faculty of Engineering, \\ Universiti Putra Malaysia, 43400 UPM, Serdang, Selangor, Malaysia \\ ${ }^{2}$ Laboratory of Bio-Composite Technology, Institute of Tropical Forestry and Forest Products, \\ Universiti Putra Malaysia, 43400 UPM, Serdang, Selangor, Malaysia \\ ${ }^{3}$ Department of Aerospace Engineering, Faculty of Engineering, Universiti Putra Malaysia, \\ 43400 UPM, Serdang, Selangor, Malaysia
}

Article history

Received: 20-11-2014

Revised: 20-01-2015

Accepted: 30-01-2015

Corresponding Author: Mohd Sapuan Salit Department of Mechanical and Manufacturing Engineering, Faculty of Engineering, Universiti Putra Malaysia, 43400 UPM, Serdang, Selangor, Malaysia

Email: sapuan@upm.edu.my

\begin{abstract}
Proper material selection enhances both desired physical and meta-physical properties of the end user products. Due to the growing awareness of the environmental issues as well as the industrial sustainability, the Natural Fiber Composites (NFCs) have recently emphasized to be implemented in various industrial applications. The final product features of such composites depend on the integrated characteristics of both matrix and fillers properties. Selecting an appropriate natural fiber type to form an NFC is affected by several factors and criteria. Up-to-date, natural fibers are evaluated regarding limited number of criteria. This study, introduces a proper integrated evaluation and selection scheme for the natural fibers and their capabilities considering integrated evaluation. Results demonstrate that better evaluation of natural fibers regarding wide range of criteria would lead to better decisions regarding selecting the suitable NFCs for industrial applications and enhance achieving better performance. Such evaluations should consider combined economic and environmental characteristics as well as technical ones. New potential fiber types can be discovered and utilized through better evaluations using combined desired criteria.
\end{abstract}

Keywords: Natural Fibers, Fibers' Selection, Date Palm Fibers, Polymeric Composites, Capability Performance, Conflicting Criteria

\section{Introduction}

Proper material selection became crucial process in engineering to achieve both successful sustainable designs and customer satisfaction attributes (AL-Oqla and Sapuan, 2014; Alves et al., 2010; Pickering, 2008; Hayajneh et al., 2005). The implementation of new materials as well as bio-composites in a specific industrial sector is limited by several constrains and factors (AL-Oqla and Sapuan, 2014; Dweiri and Al-Oqla, 2006; Luz et al., 2010; Blennow et al., 2014; Sgroi et al., 2014a; 2014b; Hayajneh et al., 2008; Asfar and AL-Oqla, 2003). Therefore, selecting the most suitable material type for a particular application is a complex matter where proper decisions have to be taken utilizing the pairwise comparisons, which is the base of decision making process in different engineering applications (Dweiri and Al-Oqla, 2006; AL-Oqla and Hayajneh, 2007; Al-Oqla and
Omar, 2012; 2014; Al-Widyan and Al-Oqla, 2011; 2014; Dalalah et al., 2010; AL-Oqla et al., 2015a).

NFCs became recently highly valuable type of ecofriendly cheap alternative materials (Alves et al., 2010; AL-Oqla et al., 2014a; Sapuan et al., 2013; AL-Oqla et al., 2015b; Testa et al., 2014a; 2014b; Di Trapani et al., 2014). Such materials have been emerged in different applications because of their desired properties (Pickering, 2008; Sgroi et al., 2014a; AL-Oqla et al., 2015a; 2014b; Fairuz et al., 2014; Squatrito et al., 2014; Tudisca et al., 2013; Asfar and AL-Oqla, 2002). The wide desired advantages of such composites including light weights, low cost, high specific properties, as well as recyclability and degradability characteristics made them proper alternatives for the traditional composites in modern green products. Several investigations regarding NFCs competitiveness and capabilities as alternative materials had been 
conducted (Blennow et al., 2014; Sapuan et al., 2013; AL-Oqla et al., 2015b; 2014b; Abdal-Hay et al., 2012; Mir et al., 2013; Sahari et al., 2014).

Several studies had investigated and addressed the competitiveness, as well as capabilities and suitability of natural fibers in polymeric matrices. Most of researches focused on the mechanical properties, manufacturing processes, chemical modifications to improve fiber/polymer compatibility, as well as other technical issues. Some tried to compare between different natural fiber composites regarding certain purposes and applications. Alves et al. (2010; Mir et al., 2013; Sarikanat, 2010) studied the properties of jute/plastic composites considering several investigated characteristics such as crystallinity, thermal stability, durability, fiber modification and weathering resistance. Moreover, the suitability of such composite to the automotive industry was also investigated throughout eco-design components. In addition, Pickering et al. (2007) extensively investigated PP composites reinforced with hemp fibers throughout the injection molding process. Authors studied fibers modifications and treatments in addition to the optimization of the hemp fiber quality. Besides, Taniguchi (2001) had utilized various cellulose fibers derived from natural sources like wood pulp, cotton, hemp and seaweed, etc. In that study rotating twin disks with shear stress was used to produce Micro-Fibrillated Cellulose (MFC). Moreover, natural fiber composites were examined for automotive components throughout eco-design assessment using bagasse/PP composites by (Luz et al., 2010). Furthermore, the appropriateness of the natural fiber composites was examined by both eco-design and parametric studies for industrial applications. It was reported that (Huda et al., 2008) performed impact tests to study the impact strength of the bamboo fiber/PLA composites. According to their results, the fibers treatment processes were able to improve the adhesion forces between the matrix and the fillers which leaded to an improvement in the impact strength. Such treatments also provided effective resistance to micro propagation during the impact. Besides, a comparison between biobased plastics with petrochemical plastics was conducted by (Shen et al., 2009). This was performed regarding their technical and market potentials. They have presented recommendations for better understanding of the potentials of bio-based plastics and petrochemical ones.

On the other hand and based on the literature, there were little studies regarding precise selections of the proper Natural Fiber Composites (NFCs) for a particular application. Sapuan et al. (2011) have implemented AHP method to select the proper material for automotive dashboard panel. The properties of materials considered in that study were limited to density, young modulus and tensile strength. Moreover, Cheung et al. (2009) have discussed the potential of natural fiber composites through mechanical and thermal properties of the animal based fiber composites. They have mentioned the potential of both plant and animal for the biomedical engineering applications. They also introduced some factors to be considered in screening general materials for that branch of applications including being bio-inert, bi-functional and bio-active.

The NFCs final products' performance and properties strongly depend on the properties of their individual constituencies as well as the polymer/filler interfacial characteristics. Based on literature; proper evaluation of NFCs composites for industrial applications is not enough discussed regarding wide range of desired criteria. On consequence, there is a lake of information regarding selecting the proper natural fiber composite materials for many applications. This is due to the large possibilities of generating new natural fiber composite materials with novel properties (AL-Oqla et al., 2015a; Kalia et al., 2011).

Therefore, further comparisons between the NFCs constituents (fillers and matrices) are still needed in an extensive manner regarding combined and integrated desired criteria and factors that may affect their selection in different applications to end up with proper consistent informative selection decisions about the natural fibers capabilities. This in order would dramatically help designers and decision makers to reach the best choice of NFC materials according to their design criteria and limitations. Consequently, this study aims to elaborate more desired characteristics that designers have to take into consideration regarding selecting NFC materials and their constituents to achieve better performance to their designs. Also, to conduct some pairwise comparisons between different fiber types regarding some selective criteria to emphasize the need for better NFCs evaluations regarding further integrated criteria.

\section{Materials and Methods}

To develop and enhance better evaluations of the natural fibers and their capabilities, necessary factors for their selection in the bio-based composites were determined. These factors were then integrated and utilized to express the potential capabilities of the available natural fibers through a combined evaluation scheme. The considered evaluation criteria included physical, chemical, mechanical as well as economic characteristics. To expand the future sustainable design possibilities, categories of criteria were utilized to evaluate fibers' capabilities to enhance achieving better decisions regarding selecting the most appropriate fiber type for polymeric based composites. To illustrate the effectiveness of such desired keen evaluations on the selection process, pairwise comparisons have been conducted between fibers regarding both single and integrated criteria. For each considered factor, an average 
value was used for the comparison purposes. Each comparison was interpreted in a proper separate figure to facilitate addressing the variations in fiber's capabilities.

\section{Results}

The complete NFCs attributes and capabilities depend on the physical and chemical composition of the inherent materials. Therefore, NFCs are to be investigated regarding many different features and properties before being considered to be used in any particular application. Such considerable criteria of selecting the natural fiber composite products can be according to Natural Fiber Properties (NFP), Polymer Base Properties (PBP), Composite Characteristics (CC) and Composite Performance (CP) (AL-Oqla and Sapuan, 2014), where different attributes and characteristics have to be investigated and taken into account to reach better evaluations of the NFC materials like physical, mechanical, chemical, biological and environmental properties as well as toxicity, bio-stability, life cycle, durability, biodegradability, weather resistance, occupational health and safety. Criteria that affect selection of natural fibers are shown in Fig. 1. Such criteria can be the key driver for the industry to enhance selection the most appropriate NFC materials for a given application through better selection of the composite constituents.

Comparing various natural fiber types considering wide desired criteria required reliable date from keen experimental works (AL-Oqla and Sapuan, 2014; Pickering, 2008; AL-Oqla et al., 2014a; 2014b; Pilla, 2011). Various properties of the available natural fibers are shown in Table 1. In such comparisons, the average values of various properties were utilized.

Comparisons between different natural fiber types namely coir, date palm, hemp, sisal, flax and jute are conducted regarding their specific modulus of elasticity and specific strength as shown in Fig. 2. and 3 respectively. It can be clearly shown that natural fibers vary in their physical and mechanical properties. These comparisons actually compounded fibers' modulus of elasticity and specific strength relative to their densities to give more relative information about different fiber types.

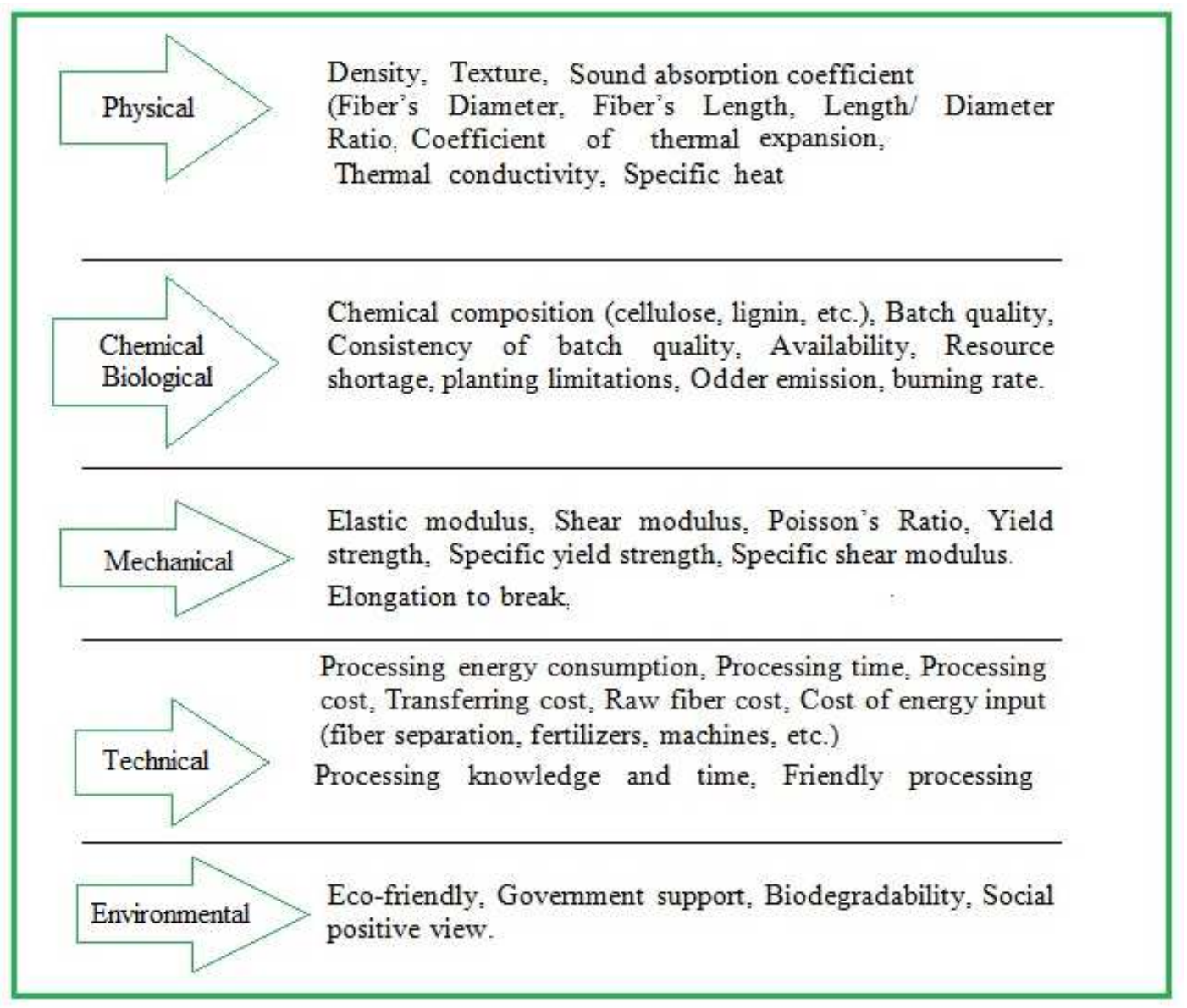

Fig. 1. Criteria affect the selection of the natural fibers for NFC materials. (Reproduced from (AL-Oqla and Sapuan, 2014)) 


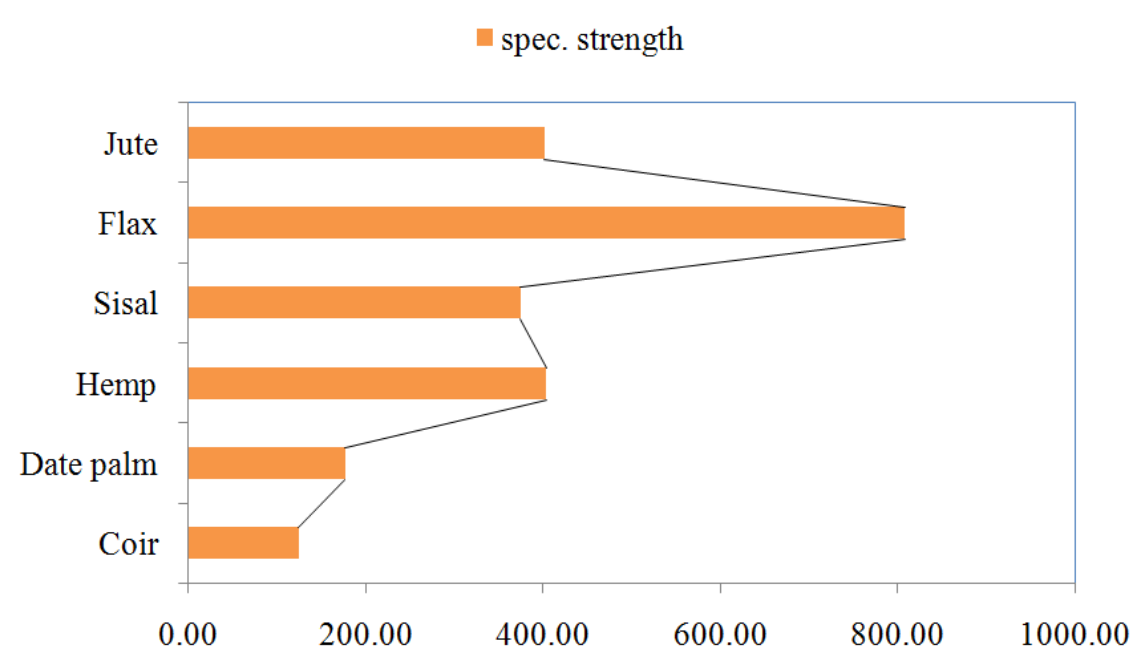

Fig. 2. Comparison of different natural fiber types regarding specific strength

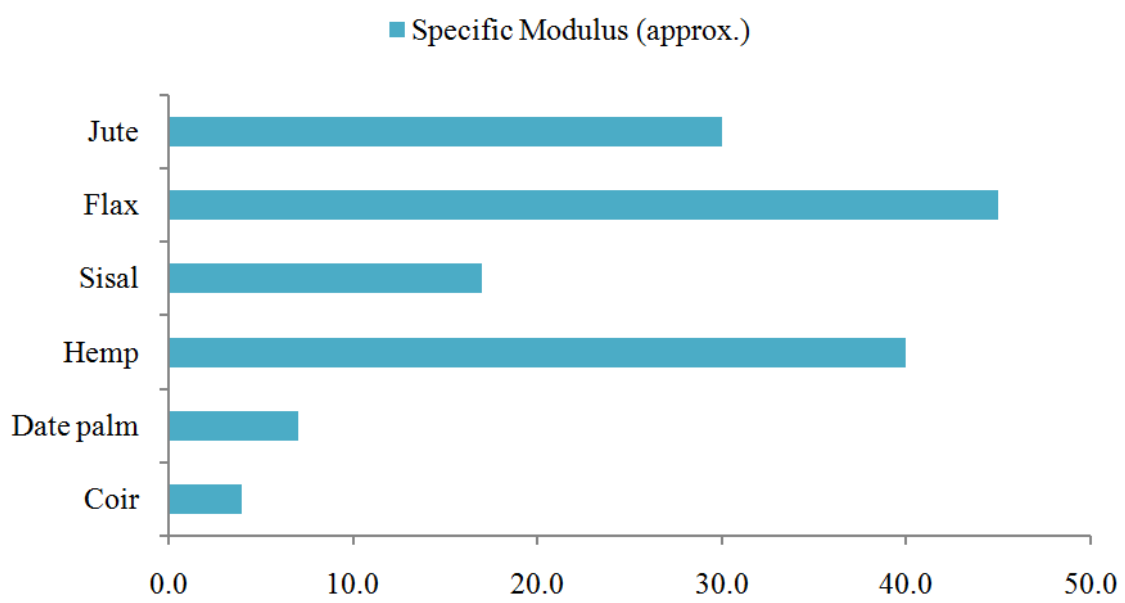

Fig. 3. Comparison of different natural fiber types regarding specific modulus

Table 1. Various properties of the commonly used fibers

\begin{tabular}{lllllll}
\hline Fiber type & Coir & Date Palme & Flax & Hemp & Jute & Sisal \\
\hline Density $\left(\mathrm{g} / \mathrm{cm}^{3}\right)$ & $1.15-1.46$ & $0.9-1.2$ & $1.4-1.5$ & $1.4-1.5$ & $1.3-1.49$ & $1.33-1.5$ \\
Tensile Strength (Mpa) & $95-230$ & $97-275$ & $343-2000$ & $270-900$ & $320-800$ & $363-700$ \\
Tensile Modulus (Gpa) & $2.8-6$ & $2.5-12$ & $27.6-103$ & $23.5-90$ & $8-78$ & $9-38$ \\
Specific Modulus & 4 & 7 & 45 & 40 & 30 & 17 \\
Elongation to Break (\%) & $15-51.4$ & $2-19$ & $1.2-3.3$ & $1-3.5$ & $1-1.8$ & $2-7$ \\
Cellulose (wt \%) & $32-43.8$ & 46 & $62-72$ & $68-74.4$ & $59-71.5$ & $60-78$ \\
Hemicellulose (wt \%) & $0.15-20$ & 18 & $18.6-20.6$ & $15-22.4$ & $13.6-20.4$ & $10-14.2$ \\
Lignin (wt \%) & $40-45$ & 20 & 2.3 & $3.7-10$ & $11.8-13$ & $8-14$ \\
Moisture Content (wt \%) & 8 & $5-12.1$ & $8-12$ & $6.2-12$ & $12.5-13.7$ & $10-22$ \\
Cost per weight (USD/Kg) & 0.3 & 0.02 & 9.0 & 1.2 & 0.3 & 1.0 \\
\hline
\end{tabular}

\section{Discussion}

It is clear that flax, hemp and jute are the best in both cases of specific strength and specific modulus. But further investigations regarding wider criteria rather than physical and mechanical properties are needed to make more realistic informative decisions regarding the best fiber type. That is; further criteria like cost will change the priority of the previous three fiber types as seen in Fig. 4 where the specific strength to the cost ratio comparisons were conducted. It is obvious that date palm fibers are the best type among all other types if further economic criteria are considered. It can be seen that date Palm fiber is about four times better than jute. 
On the other hand, a chemical composition investigation between commonly used fibers in addition to the date palm one regarding all of cellulose, lignin and hemicellulose contents reveals the effect of cellulose content in the mechanical properties of such fibers. Such comparisons are illustrated in Fig. 5. It can be deduced that fibers with higher cellulose contents possess better mechanical properties. That is; sisal, hemp, flax and jute have relative higher values of specific moduli and specific strengths than coir and date palm fibers (Fig. 2 and 3) as they have higher cellulose contents (Fig. 5).

On the other side, the amount of cellulose content has a negative effect on other beneficial characteristics of the natural fibers, as that of the elongation to break one. A comparison between various fibers regarding the elongation to break property (Fig. 6) reveals that coir and date palm have much better elongation to break characteristics than other fibers because of their lower contents of cellulose. This in order make the selection of the best natural fiber type for polymeric composites is a complex matter with conflicting criteria problem. Therefore, extensive comparisons of fibers are still needed to be conducted regarding wide beneficial criteria to establish a date base for more proper evaluations of the available natural fibers' capabilities. This in order would dramatically lead to expand their implementations in various green products to enhance environmental as well as industrial sustainability. Moreover, proper comparative studies between fibers' capabilities would enhance finding new potential fiber types with optimum conflicting desired characteristics that may improve the overall desired characteristics of the bio-based materials like that of date palm fibers.

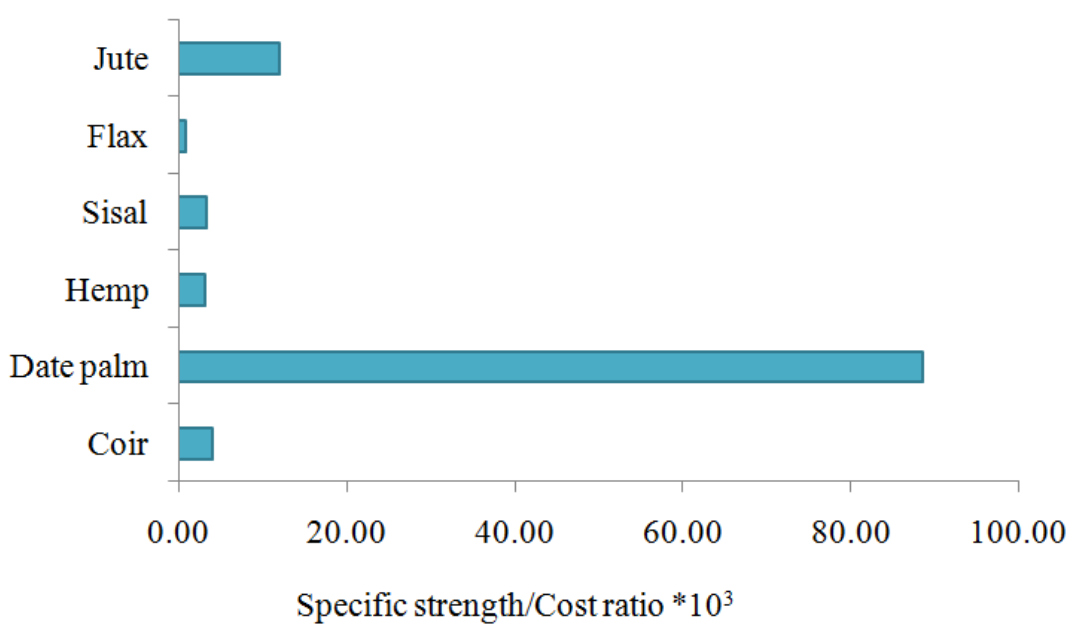

Fig. 4. Comparison of different natural fiber types regarding combined specific strength to cost ratio criterion

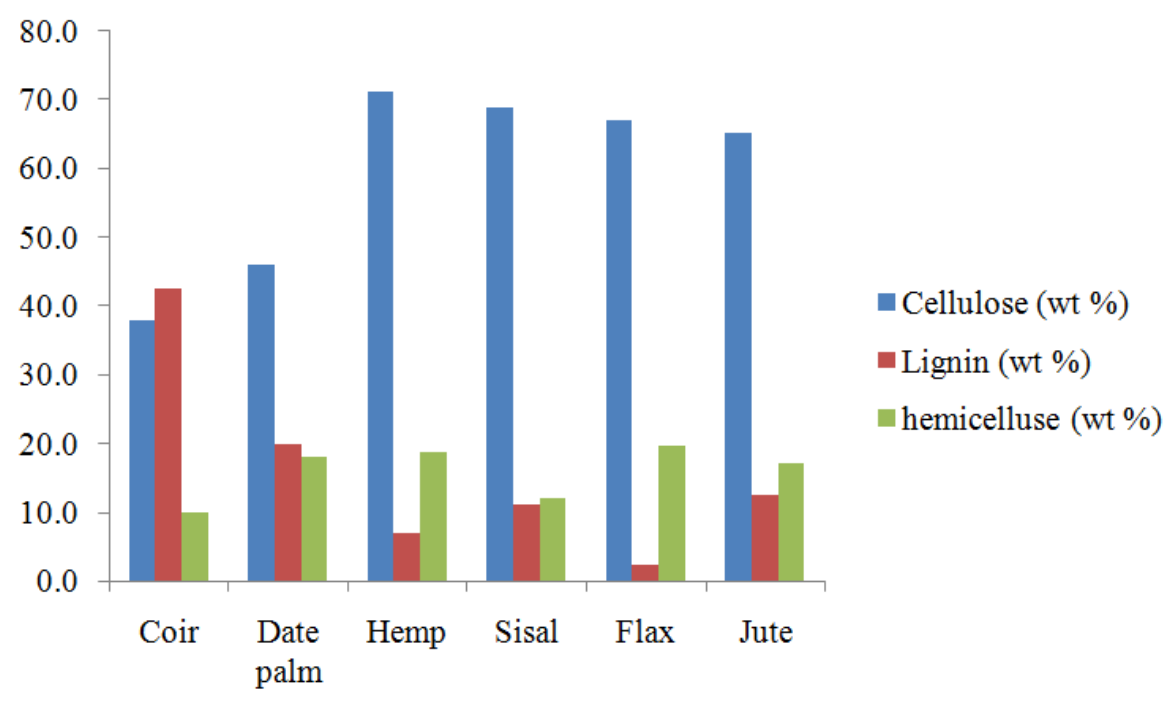

Fig. 5. Comparison of chemical composition of natural fibers 


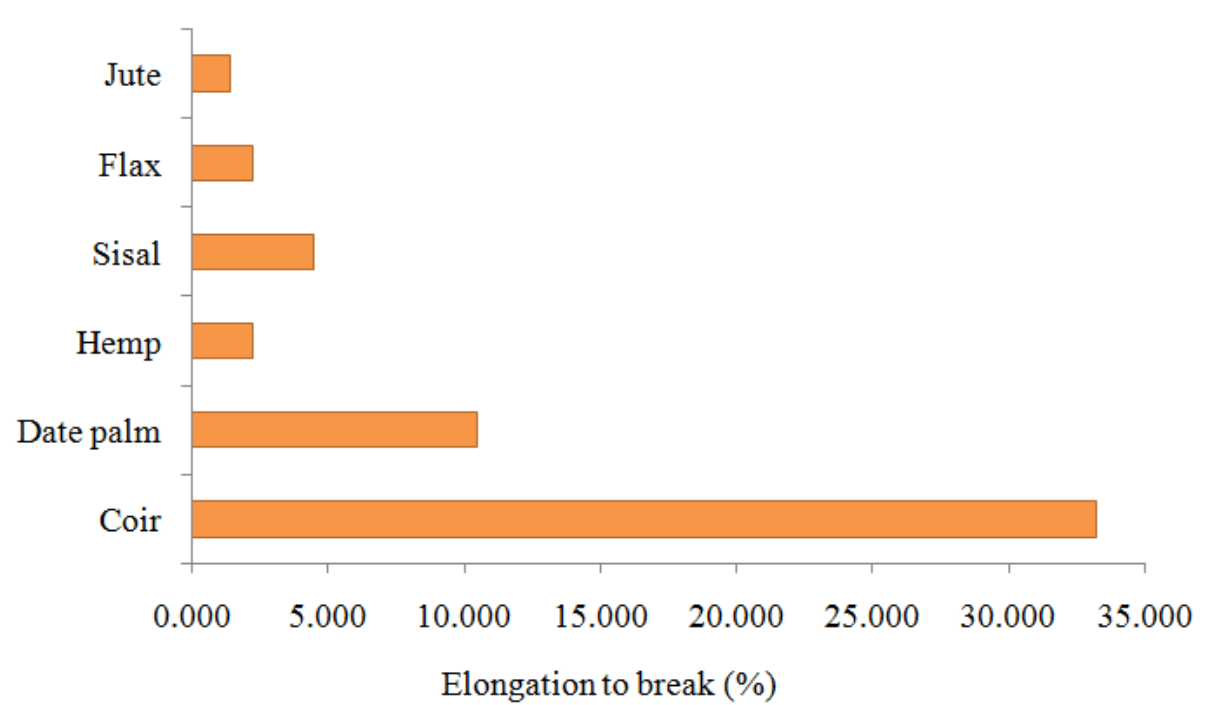

Fig. 6. Comparison between various fibers regarding elongation to break property

\section{Conclusion}

Selecting an appropriate natural fiber type to form NFCs is affected by several criteria and considered as a multi-criteria decision making problem. Better evaluations of natural fibers regarding wide range of criteria have several advantages. This can lead to better informative decisions regarding selecting the suitable NFCs for industrial applications on one hand, and enhance achieving better performance on the other. Evaluations of NFCs' constituents should consider combined economic and environmental characteristics as well as technical ones to be able to achieve more reasonable confident decisions. Moreover, new potential fiber types can be discovered and utilized through better evaluations using wider desired criteria.

\section{Acknowledgment}

The authors would like to acknowledge the Universiti Putra Malaysia for supporting this work through an International Graduate Research Fellowship (IGRF).

\section{Author's Contributions}

All authors equally contributed in this work.

\section{Ethics}

This article is original and contains unpublished material. The corresponding author confirms that all of the other authors have read and approved the manuscript and no ethical issues involved.

\section{References}

Abdal-Hay, A., N.P.G. Suardana, D.Y. Jung and K.S. Choi et al., 2012. Effect of diameters and alkali treatment on the tensile properties of date palm fiber reinforced epoxy composites. Int. J. Precis. Eng. Manuf., 13: 1199-1206. DOI: $10.1007 / \mathrm{s} 12541-012-0159-3$

Al-Oqla, F.M. and A.A. Omar, 2012. A decisionmaking model for selecting the GSM mobile phone antenna in the design phase to increase over all performance. Progress Electromagnetics Res. C, 25: 249-269.

DOI: 10.2528 /PIERC 11102702

Al-Oqla, F.M. and A.A. Omar, 2014. An expert-based model for selecting the most suitable substrate material type for antenna circuits. Int. J. Electron. DOI: $10.1080 / 00207217.2014 .961041$

AL-Oqla, F.M. and M.T. Hayajneh, 2007. A design decision-making support model for selecting suitable product color to increase probability. Design Challenge Conference: Managing Creativity, Innovation and Entrepreneurship. Amman, Jordan.

AL-Oqla, F.M. and S.M. Sapuan, 2014. Natural fiber reinforced polymer composites in industrial applications: Feasibility of date palm fibers for sustainable automotive industry. J. Cleaner Product., 66: 347-354.

DOI: $10.1016 /$ j.jclepro.2013.10.050

AL-Oqla, F.M., M.S. Salit, M.R. Ishak and AA. Nuraini, 2015b. A novel evaluation tool for enhancing the selection of natural fibers for polymeric composites based on fiber moisture content criterion. BioRes., 10: 299-312. 
AL-Oqla, F.M., M.S. Sapuan, M.R. Ishak and N.A. Aziz, 2014b. Combined multi-criteria evaluation stage technique as an agro waste evaluation indicator for polymeric composites: Date palm fibers as a case study. BioRes., 9: 4608-4621.

AL-Oqla, F.M., O.Y. Alothman, M. Jawaid, S. Sapuan and M. Es-Saheb, 2014a. Processing and Properties of Date Palm Fibers and its Composites. In: Biomass and Bioenergy: Processing and Properties, Hakeem, K.R., M. Jawaid and U. Rashid (Eds)., Springer, Cham, ISBN-10: 3319076418 , pp: 1-25.

AL-Oqla, F.M., S.M. Sapuan, M.R. Ishak, 2015a. Decision making model for optimal reinforcement condition of natural fiber composites. Fibers Polym., 16: 153-163.

Alves, C., P. Ferrão, A. Silva, L. Reis and M. Freitas et al., 2010. Ecodesign of automotive components making use of natural jute fiber composites. J. Cleaner Product., 18: 313-327.

DOI: $10.1016 /$ j.jclepro.2009.10.022

Al-Widyan, M.I. and F.M. Al-Oqla, 2011. Utilization of supplementary energy sources for cooling in hot arid regions via decision-making model. Int. J. Eng. Res. Applic., 1: 1610-1622.

Al-Widyan, M.I. and F.M. AL-Oqla, 2014. Selecting the most appropriate corrective actions for energy saving in existing buildings $\mathrm{A} / \mathrm{C}$ in hot arid regions. Build Simul., 7: 537-545.

DOI: $10.1007 / \mathrm{s} 12273-013-0170-3$

Asfar, K. and F.M. AL-Oqla, 2002. A cable manipulation technique for cargo pendulations reduction. Proceedings of the 9th Nonlinear Vibrations, Stability and Dynamics of Structures Conference, Jul. 28-Aug. 1, Virginia Tech, Blacksburg, Virginia-USA.

Asfar, K.R. and F.M. AL-Oqla, 2003. Controlling pendulations of tethered satellites using tether manipulation technique. Proceedings of the 54th International Astronautical Congress, BremenGermany, Under Supervision of International Astronautical Federation, Sept. 29-Oct. 3, pp: 1-5.

Blennow, K., E. Persson, M. Lindner, S.P. Faias and M. Hanewinkel, 2014. Forest owner motivations and attitudes towards supplying biomass for energy in Europe. Biomass Bioenergy, 67: 223-230. DOI: 10.1016/j.biombioe.2014.05.002

Cheung, H.Y., M.P. Ho, K.T. Lau, F. Cardona and D. Hui, 2009. Natural fibre-reinforced composites for bioengineering and environmental engineering applications. Composites Part B: Eng., 40: 655-663. DOI: 10.1016/j.compositesb.2009.04.014

Dalalah, D., F.M. Al-Oqla and M. Hayajneh, 2010. Application of the Analytic Hierarchy Process (AHP) in multi-criteria analysis of the selection of cranes. Jordan J. Mech. Industl. Eng., 4: 567-578.
Di Trapani, A.M., R. Squatrito, M. Foderà, R. Testa and S. Tudisca et al., 2014. Payment for environmental services for the sustainable development of the territory. Am. J. Environ. Sci., 10: 480-488.

DOI: 10.3844 /ajessp.2014.480.488

Dweiri, F. and F.M. Al-Oqla, 2006. Material selection using analytical hierarchy process. Int. J. Comput. Applic. Technol., 26: 182-189. DOI: 10.1504/IJCAT.2006.010763

Fairuz, A.M., S.M. Sapuan, E.S. Zainudin and C.N.A. Jaafar, 2014. Polymer composite manufacturing using a pultrusion process: A review. Am. J. Applied Sci., 11: 1798-1810. DOI: 10.3844 /ajassp.2014.1798.1810

Hayajneh, M.T., S. Radaideh, F.M. AL-Oqla and F.A. Al-Omari, 2005. Reduction of pendulations in overhead cranes carrying massive loads on long cables using a cable reeling technique. Int. J. Eng. Simulat.

Hayajneh, M.T., S.M. Radaideh, F.M. AL-Oqla and I. Nejdawi, 2008. Reductions of pendulations of overhead cranes under the effect of air resistance by a cable manipulation manner. Proceedings of the 5th International Symposium on Mechatronics and its Applications, May 27-29, IEEE Xplore Press, Amman, pp: 1-6.

DOI: 10.1109/ISMA.2008.4648840

Huda, M., L. Drzal, D. Ray, A. Mohanty and M. Mishra, 2008. Natural-fiber composites in the automotive sector. Properties and performance of natural-fibre composites. Woodhead Publishing Ltd, England.

Kalia, S., A. Dufresne, B.M. Cherian, B. Kaith and L. Avérous et al., 2011. Cellulose-based bio- and nanocomposites: A review. Int. J. Polymer Sci., 2011: 1-35. DOI: $10.1155 / 2011 / 837875$

Luz, S.M., A. Caldeira-Pires and P. Ferrao, 2010. Environmental benefits of substituting talc by sugarcane bagasse fibers as reinforcement in polypropylene composites: Ecodesign and LCA as strategy for automotive components. Resour. Conserv. Recycl., 54: 1135-1144.

DOI: 10.1016/j.resconrec.2010.03.009

Mir, S.S., N. Nafsin, M. Hasan, N. Hasan and A. Hassan, 2013. Improvement of physico-mechanical properties of coir-polypropylene biocomposites by fiber chemical treatment. Materials Design, 52: 251257. DOI: $10.1016 /$ j.matdes.2013.05.062

Pickering, K., 2008. Properties and Performance of NaturalFibre Composites. 1st Ed., Elsevier, Cambridge, England, ISBN-10: 1845694597, pp: 576.

Pickering, K.L., G.W. Beckermann, S.N. Alam and N.J. Foreman, 2007. Optimising industrial hemp fibre for composites. Composites Part A: Applied Sci. Manufactur., 38: 461-168.

DOI: 10.1016/j.compositesa.2006.02.020 
Pilla, S., 2011. Handbook of Bioplastics and Biocomposites Engineering Applications. 1st Edn., John Wiley and Sons, Hoboken, NJ., ISBN-10: 1118177045 , pp: 620.

Sahari, J., S.M. Sapuan, E.S. Zainudin and M.A. Maleque, 2014. Biodegradability and mechanical behaviour of sugar palm starch based biopolymer. Am. J. Applied Sci., 11: 1836-1840. DOI: 10.3844 /ajassp.2014.1836.1840

Sapuan, S.M., F.L. Pua, Y.A. El-Shekeil and F.M. AL-Oqla, 2013. Mechanical properties of soil buried kenaf fibre reinforced thermoplastic polyurethane composites. Materials Design, 50: 467-670. DOI: 10.1016/j.matdes.2013.03.013

Sapuan, S.M., J.Y. Kho, E.S. Zainudin, Z. Leman and B. Ali et al., 2011. Materials selection for natural fiber reinforced polymer composites using analytical hierarchy process. Ind. J. Eng. Mat. Sci., 18: 255-267.

Sarikanat, M., 2010. The influence of oligomeric siloxane concentration on the mechanical behaviors of alkalized jute/modified epoxy composites. J. Reinf. Plast. Compos., 29: 807817. DOI: $10.1177 / 0731684408100700$

Sgroi, F., A.M. Di Trapani, R. Testa and S. Tudisca, 2014b. Strategy to increase the farm competitiveness. Am. J. Agric. Biol. Sci., 9: 394400. DOI: 10.3844/ajabssp.2014.394.400

Sgroi, F., S. Tudisca, A.M. Di Trapani, R. Testa and R. Squatrito, 2014a. Efficacy and efficiency of Italian energy policy: The case of PV systems in greenhouse farms. Energies, 7: 3985-4001.

DOI: $10.3390 /$ en7063985
Shen, L., J. Haufe and M.K. Patel, 2009. Product overview and market projection of emerging biobased plastics PRO-BIP 2009. Universiteit Utrecht. www.uu.nl

Squatrito, R., F. Sgroi, S. Tudisca, A.M.D. Trapani and R. Testa, 2014. Post feed-in scheme photovoltaic system feasibility evaluation in Italy: Sicilian case studies. Energies, 7: 7147-7165.

DOI: $10.3390 /$ en 7117147

Taniguchi, T., 2001. Nanofibrils from natural organic fibers as industrial materials. Jpn. Kokai Tokkyo Koho.

Testa, R., A.M. Di Trapani, F. Sgroi and S. Tudisca, $2014 \mathrm{~b}$. Economic analysis of process innovations in the management of olive farms. Am. J Applied Sci., 11: 1486-1491. DOI: 10.3844/ajassp.2014.1486.1491

Testa, R., A.M. Di Trapani, M. Foderà, F. Sgroi and S. Tudisca, 2014a. Economic evaluation of introduction of poplar as biomass crop in Italy. Renewable Sustainable Energy Rev., 38: 775-780. DOI: 10.1016/j.rser.2014.07.054

Tudisca, S., A.M. Di Trapani, F. Sgroi, R. Testa and R. Squatrito, 2013. Economic analysis of PV systems on buildings in Sicilian farms. Renewable Sustainable Energy Rev., 28: 691-701. DOI: $10.1016 /$ j.rser.2013.08.035 